\title{
Photoexcitation of the 0 intermediate of bacteriorhodopsin and its mutant E204Q
}

\author{
R. Tóth-Boconádi ${ }^{1}$, S. G. Taneva ${ }^{2}$ and L. Keszthelyi ${ }^{1, *}$ \\ ${ }^{1}$ Institute of Biophysics, Biological Research Centre of the Hungarian Academy of Sciences, H-6701 Szeged, Hungary \\ ${ }^{2}$ Institute of Biophysics, Bulgarian Academy of Sciences, Sofia, Bulgaria
}

\begin{abstract}
Photoexcitation of the intermediates of the bacteriorhodopsin photocycle provides valuable information on their particular rôles. Photoelectric responses from the $\mathrm{K}, \mathrm{M}$ and $\mathrm{N}$ forms are available but the electric response of the excited $\mathrm{O}$ intermediate is poorly known. Double flash experiments with varying time delays between the flashes have been carried out, revealing that the photoreactions of the $\mathrm{O}$ intermediates in wild-type bacteriorhodopsin and in mutant E204Q are quite different. The photoreaction of the $\mathrm{O}$ intermediate of the wild-type bacteriorhodopsin is more-or-less similar to that of the bR-state, i.e. it translocates charge, whereas in the mutant E204Q the photoreaction is merely a small disturbance involving minor internal charge motions.
\end{abstract}

Keywords: double flash excitation, orientation, photocurrent, proton pump, purple membrane, retinal protein

\section{INTRODUCTION}

The light-driven proton pump, bacteriorhodopsin (bR), in Halobacterium salinarum carries out its function proceeding through intermediates named $\mathrm{J}$, $\mathrm{K}, \mathrm{L}, \mathrm{M}, \mathrm{N}$, and $\mathrm{O}$ (for recent reviews see [1,2]). To understand the molecular mechanism of light-energy transduction many methods are used [3]. One of them, photoexcitation of the intermediates, provides valuable information on their particular rôle in the photocycle [4]. Electric responses of the photoreactions of the intermediates turned out to be indispensable in understanding the mechanism of proton translocation. It became clear that illumination of the $\mathrm{M}$ intermediate with blue light terminated proton transfer [5]. In time-resolved studies negative currents were registered [6,7] (negative current is defined relative to the positive direction of undisturbed proton transport). This negative photoelectric response helped to verify the existence of a very long living $\mathrm{M}$ intermediate in the photocycle of the bR mutant D96N [8]. In a recent paper we published data on the photoelectric responses of the $\mathrm{N}$ intermediate [9].

The $\mathrm{O}$ intermediate has been rather elusive in the case of wild-type bR (WTbR). Later, it became clear that it accumulates at low $\mathrm{pH}$ and high temperature $[10,11]$. The mutant E204Q has a long living O even at normal $\mathrm{pH}$ and room temperature $[12,13]$.

${ }^{*}$ Author for correspondence.
The study of the photoelectric responses of $\mathrm{O}$, accumulating during the photocycle of WTbR and E204Q, is of special interest not only because electric responses from $\mathrm{O}$ excitation are less known but also because the late intermediates are still in the focus of research [11]. Performing double flash excitation we found quite different photoreactions for $\mathrm{O}$ of WTbR and E204Q: a pumping photocycle occurs for WTbR and a small disturbance for the mutant E204Q.

\section{MATERIALS AND METHODS}

Purple membrane (pm) containing WTbR was separated from Halobacterium salinarum strain $\mathrm{R}_{1} \mathrm{M}_{1}$. The pm with the E204Q mutant expressed in strain L-33 was supplied by J. K. Lanyi. The membrane fragments were oriented and immobilized in polyacrylamide gel as described by Dér et al. [14]. Slabs measuring $1.6 \times 1.6 \times 0.18 \mathrm{~cm}$ were cut and soaked in a solution $\left(\approx 100 \mathrm{~cm}^{3}\right.$, containing $50 \mu \mathrm{M}$ $\mathrm{CaCl}_{2}$ at $\mathrm{pH} 4.5$ for WTbR and 7.5 for the mutant) at least overnight, and placed into cuvettes containing the same solution.

Different light sources were used in varying combinations for flash illumination: a frequencydoubled Nd YAG laser (Surelite I-10, Continuum), an excimer-driven dye laser (Lambda Physik, EMG $101 \mathrm{MSC}$ ), and a photographic flash lamp (Flash Gun P21*44, Hanimex) with a flash half time of $0.65 \mathrm{~ms}$ and whose light first passed through a water heat bath. The dyes were LC5530 fluorescein $27(550 \mathrm{~nm})$, LC5900 rhodamine 6G $(580 \mathrm{~nm})$ and LC6500 DCM $(650 \mathrm{~nm})$ (Lambdachrom laser dye). The Nd YAG 
laser and the photographic flash lamp were used for the first and the dye laser for the second flash. A laboratory-built time generator controlled the delay between the flashes. Data recording could be triggered either from the first or the second flash.

In the case of WTbR quasi-continuous illumination from a xenon lamp (PTI MOD A 1010) and a $200 \mathrm{~W}$ tungsten lamp applied through a band pass filter (maximal transmission at $536 \mathrm{~nm}$, halftransmissions at 490 and $605 \mathrm{~nm}$, "green light") and a high pass filter ( $\lambda>650 \mathrm{~nm}$, "red light"), respectively. The same time generator controlled two shutters (opening and closing time $7 \mathrm{~ms}$ ) for the two light sources. The fluence, varied by neutral filters, was measured with a light meter (LI-250, LI-COR Inc.).

Platinized Pt electrodes immersed into the solution picked up the electric signals which were amplified by a laboratory-built current amplifier, based on a Burr-Brown 3554 operational amplifier, with bandwidth set to $300 \mathrm{kHz}$ for the short and $1 \mathrm{kHz}$ for the long time recordings. The signals were digitized by computer-controlled transient recorders (Thurlby DSA-524 (Thurlby Electronics Ltd) with a thousand channels, or LeCroy $9310 \mathrm{~L}$ (LeCroy Corp.) with ten thousand channels). Absorption changes were measured at $632 \mathrm{~nm}$ with a $\mathrm{He}-\mathrm{Ne}$ laser (D5-LHP-151, Melles Griot) and a photomultiplier. The measurements were performed at $30-31^{\circ} \mathrm{C}$ for WTbR to accumulate $\mathrm{O}$ and at room temperature $\left(22-24{ }^{\circ} \mathrm{C}\right)$ for $\mathrm{E} 204 \mathrm{Q}$.

The major problem in the study of the photocycle of an intermediate is to separate the responses of two photocycles: that of the intermediate and the unavoidable excitation of the residual bR-state whose population changes with delay time between the first and the second flash. The protocol outlined in ref. [9] was followed.

\section{RESULTS}

\subsection{Wild-type bacteriorhodopsin}

It is well documented that the electric signal of light-excited WTbR starts with a fast negative signal, followed by longer-living positive components [15]. Fig. 1 shows the electric signal (panel a) and its time integral representing charge translocation (panel b).

Time integrals of the fast component at different delay times after the first flash normalized to the alternately recorded values without the first flash (squares), and the light absorption at $632 \mathrm{~nm}$ (line a) are displayed in Fig. 2. The latter is the superposition of the bleaching of bR (calculated line $b$ ) and the absorption of O. Subtracting line $b$ from line a yields the absorption of $\mathrm{O}$ (line $\mathrm{c}$ ), representing the time

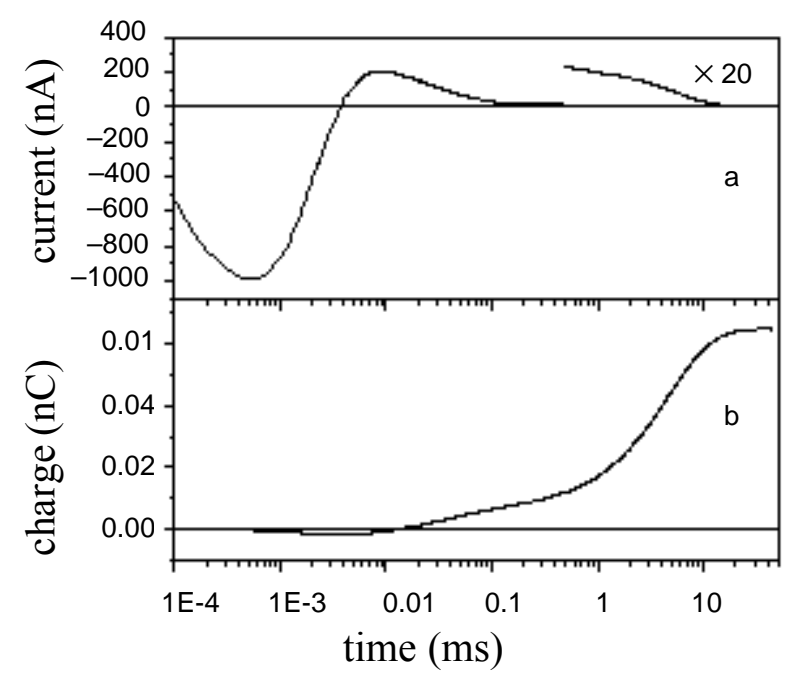

Figure 1. Electric signal for wild-type bacteriorhodopsin excited with the dye laser $(580 \mathrm{~nm})$. Panel a: current, panel $\mathrm{b}$ : its time integral, equivalent to the transported charge. The solution contained $50 \mu \mathrm{M} \mathrm{CaCl}_{2}, \mathrm{pH} 4.5$, temperature $31{ }^{\circ} \mathrm{C}$.

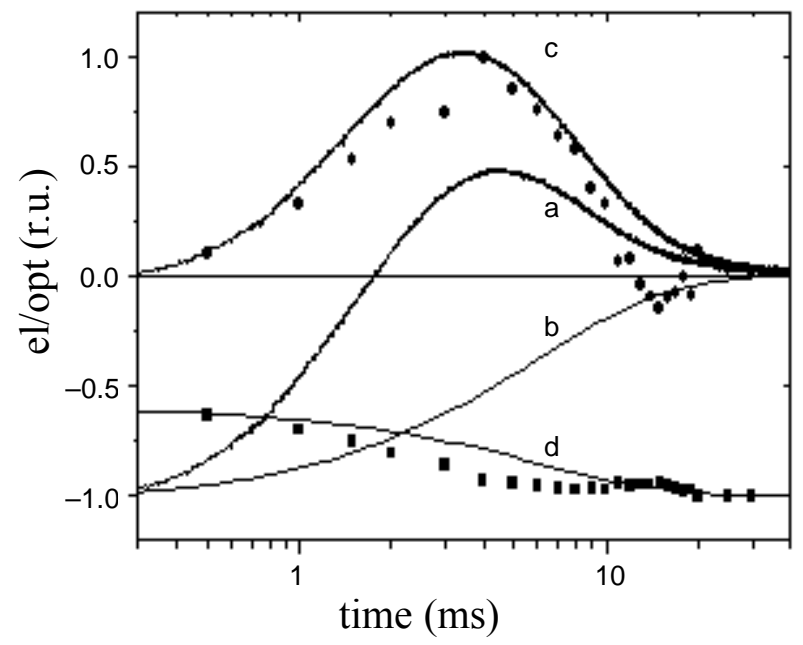

Figure 2. Processing of the electric (el) and optical (opt) data for wild-type bacteriorhodopsin. Line (a): change of absorption at $632 \mathrm{~nm}$, line (b): bleaching of bR calculated according to the function $-\exp (-(t-0.2) / 6)$ with $t$ in $\mathrm{ms}$, line (c): the difference between lines a and b, representing the concentration of O. Squares: the integrated values of the first fast electric signal measured at different delay times after the first flash (Nd YAG laser) excited with the dye laser $(650 \mathrm{~nm})$, line $(\mathrm{d})$ : calculated contribution from the excitation of the bR-state, $-0.4(1-\exp (-(t-0.2) / 6))-0.6$, circles: differences of squares and line $d$ multiplied by -1 and scaled to line c. Solution composition as in Fig. 1.

dependence of its concentration. We assume that at a delay of $0.5 \mathrm{~ms}$ the electric signal originates from the excitation of the residual bR-state and depends on the delay time as line d. The differences of the squares from line $d$ yield the electric signals attributed to the excitation of $\mathrm{O}$ (circles). The near agreement of the time courses of the electric and optical data, though small deviations occur mainly at delays above $\approx 10 \mathrm{~ms}$, is good evidence that the calculated electric responses are due to $\mathrm{O}$. 
In Fig. 3 the $\mu$ s part of the electric signals for single flash excitation of the bR-state at $650 \mathrm{~nm}$ (line b) and $\mathrm{O}$ (line a) recorded at delay $\tau=4 \mathrm{~ms}$ are compared. The fast part of the $\mathrm{O}$ signal is biphasic: it has a positive and a larger negative component.

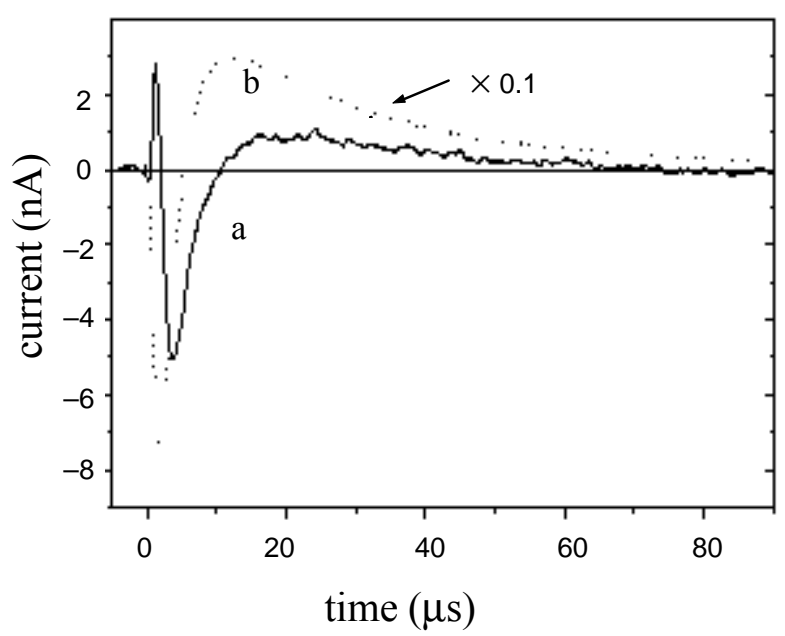

Figure 3. Electric signals for wild-type bacteriorhodopsin. (a): double flash experiment, the dye laser $(650 \mathrm{~nm})$ illuminated the sample with a delay of $4 \mathrm{~ms}$ after the first laser flash at $530 \mathrm{~nm}$ (Nd YAG laser). (b): single flash experiment, the dye laser $(650 \mathrm{~nm})$ illuminated the sample without the first flash. The recordings were triggered in both cases by the laser flash. Solution composition as in Fig. 1.

Fig. 4 shows the electric current, its time integral, and the absorption change at $632 \mathrm{~nm}$ of $\mathrm{O}$ in the $\mathrm{ms}$ time range. Line $b$ in Fig. 2 and the electric current in Fig. 4 are calculated using ratios for the bR-state and $\mathrm{O}$ excitation from Fig.2. The positive time integral is interpreted as evidence for charge translocation in

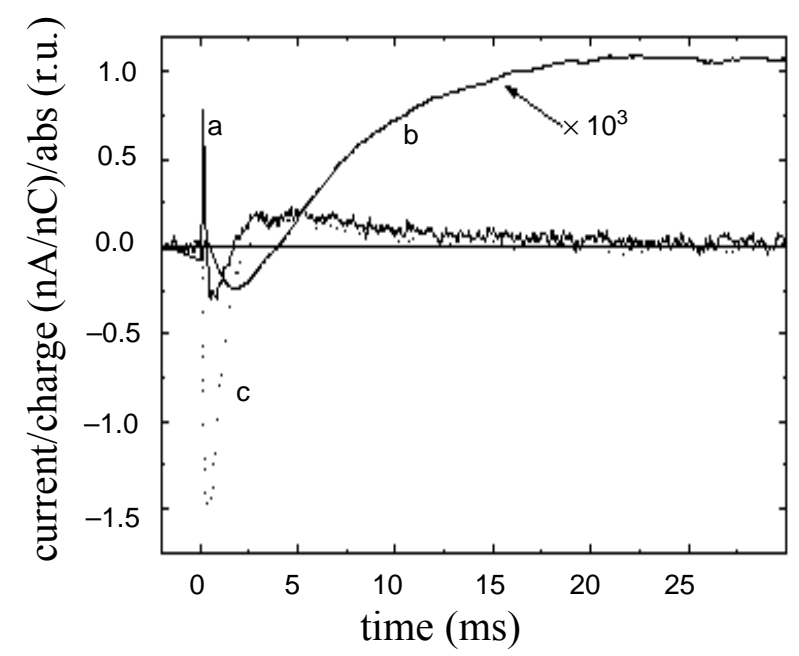

Figure 4. Electric and optical signals for the excitation of $\mathrm{O}$ of wild-type bacteriorhodopsin. The $650 \mathrm{~nm}$ laser flash illuminated the sample with a delay of $4 \mathrm{~ms}$ after the laser flash at $530 \mathrm{~nm}$. Line (a): current, line (b) time integral of the current, line (c) absorption change at $632 \mathrm{~nm}$. Solution composition as in Fig. 1. the $\mathrm{O}$ photocycle. Lifetime values of the electric and optical signals for the second flash, in adequate agreement with each other, are collected in Table 1.

Table 1.

\begin{tabular}{lcc}
\hline $\begin{array}{l}\text { Type of } \\
\text { signal }\end{array}$ & $\tau_{1}(\mathrm{~ms})$ & $\tau_{2}(\mathrm{~ms})$ \\
\hline Electric & $(-) 0.93 \pm 0.02$ & $(+) 5.7 \pm 0.4$ \\
Optical & (r) $0.90 \pm 0.01$ & (d) $7.1 \pm 0.5$ \\
\hline
\end{tabular}

Lifetimes of the components of the electric and optical signals of the $\mathrm{O}$ intermediate of wild-type bacteriorhodopsin in the ms time domain.

(For the electric signals $(+)$ indicates movement of positive charge in the pumping direction and (-) in the opposite direction. For the optical signals, (r) and (d) in front of the time values signify rise and decay respectively.)

The saturating time integral of the electric response (Fig. 4, line $\mathrm{b}$ ) indicates that $\mathrm{O}$ is a light driven pump similar to the bR-state. In order to confirm this important finding current measurements with combined "green" and "red" illumination were performed. The procedure is illustrated in Fig. 5.

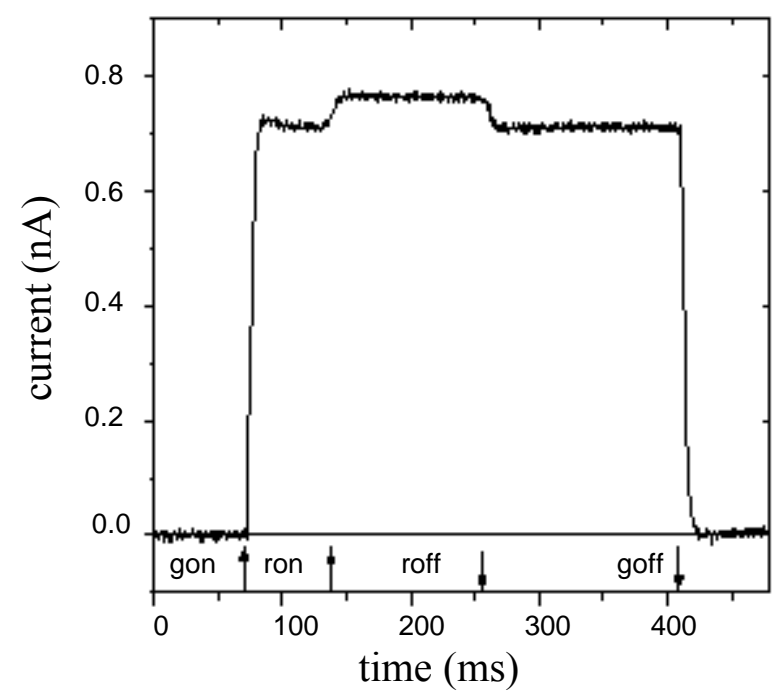

Figure 5. Current due to quasi-continuous illumination. Illumination with green light ( $\mathrm{g}$ on and $\mathrm{g}$ off, band-pass filter centred at $536 \mathrm{~nm}, 2.7 \times 10^{17}$ photons $\mathrm{cm}^{-2} \mathrm{~s}^{-1}$ ) and with red light ( $\mathrm{r}$ on and $\mathrm{r}$ off, high pass filter $>650 \mathrm{~nm}$, $2.08 \times 10^{17}$ photons $\left.\mathrm{cm}^{-2} \mathrm{~s}^{-1}\right)$. Solution composition 50 $\mu \mathrm{M} \mathrm{CaCl}_{2}, \mathrm{pH} 4.5$, temperature $25^{\circ} \mathrm{C}$.

The current due to green light increases when the sample is illuminated with additional red light. The differences between the "red + green" and "green" current for increasing green and constant red illumination ("red" current) are presented in Fig. 6 (squares). At zero green fluence the "red" current originates only from the red illumination of the bRstate. As the green light increases the population of the bR-state decreases and the population of $\mathrm{O}$ increases. Thus, the "red" current has two sources: 


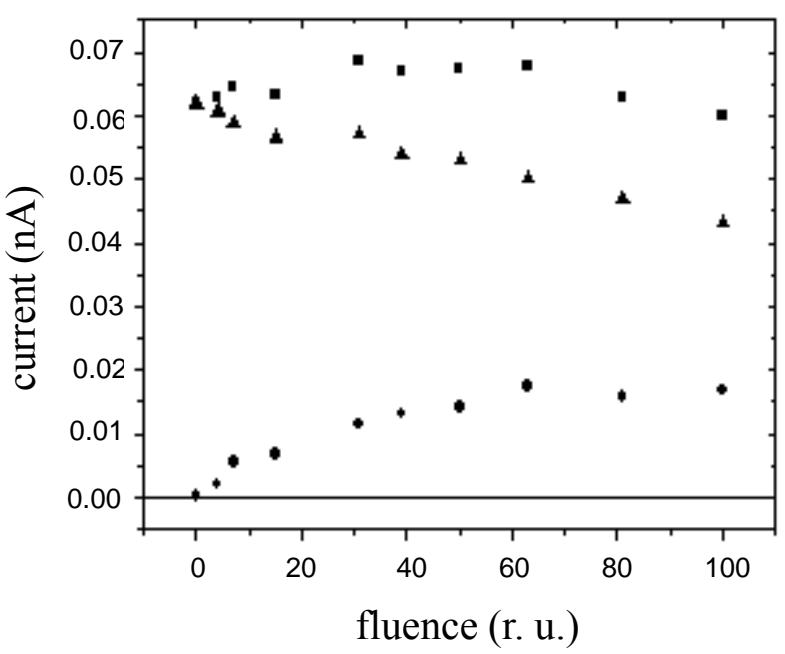

Figure 6. Squares: dependence of the "red" current (current for red + green illumination - current for green illumination) upon the fluence of green light $(100=2.7 \times$ $10^{17}$ photons $\mathrm{cm}^{-2} \mathrm{~s}^{-1}$, the red fluence was held constant at $2.08 \times 10^{17}$ photons $\mathrm{cm}^{-2} \mathrm{~s}^{-1}$ ). Triangles: the calculated "red" current for the residual bR-state. Circles: "red" current attributed to $\mathrm{O}$ for constant red illumination under increasing green illumination. Solution composition as in Fig. 5.

(1) from the bR-state; and (2) from $\mathrm{O}$, both for red light. To separate (1) and (2) the dependence of the population of the residual bR-state upon the fluence of green light was determined. The method was simple: the bR-state was excited with a dye laser at $550 \mathrm{~nm}$ at different green background fluences and the time dependence of the $\mathrm{O}$ absorption measured. There are two components: one continuous due to the continuous green excitation and one transient due to the pulsed laser excitation. The absorbance of the transient is proportional to the residual bR-state. From these absorbences the decrease of the population of the bR-state was calculated, the "red" current from source (1) decreases as shown in Fig. 6 (triangles). After subtraction (squares - triangles), the current due to the red illumination of $\mathrm{O}$ (source 2 ) is obtained (circles). The current increases and apparently reaches saturation as the $\mathrm{O}$ intermediate forms upon increasing the green light fluence.

\subsection{Mutant E204Q}

In Fig. 7 two lines in the $\mu$ s domain are presented: line $\mathrm{a}$ is the electric signal for bR-state excitation, line $b$ is recorded at a delay of $40 \mathrm{~ms}$ after the photographic flash. Both signals are excited with the dye laser $(650 \mathrm{~nm})$. The two signals are very different: line $a$ ) shows small negative and large positive amplitudes, line $b$ has large negative and small positive amplitudes. It may be seen that at $650 \mathrm{~nm}$ the negative component of the bR-state signal compared to that of the double flash signal is small.

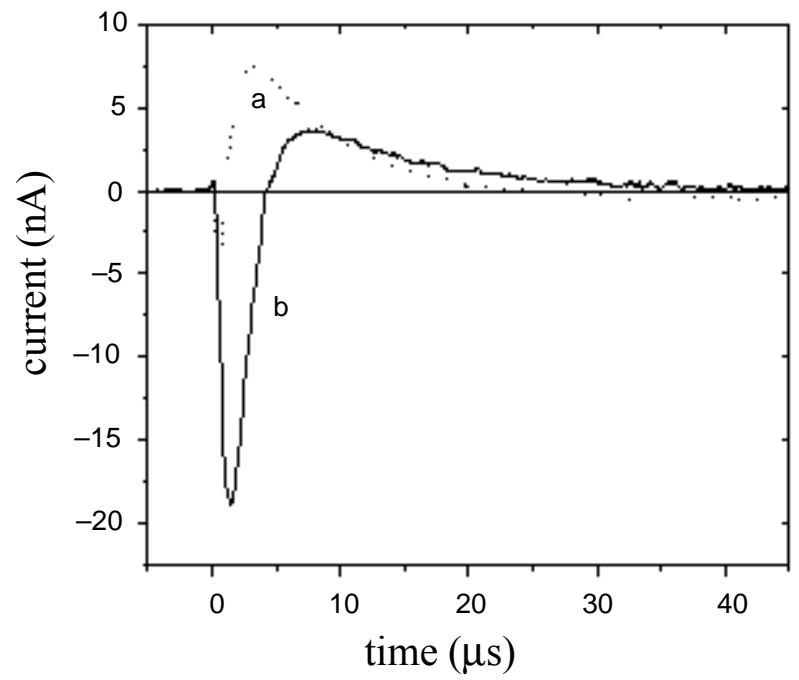

Figure 7. Electric signals from mutant E204Q excited with a laser flash (wavelength $=650 \mathrm{~nm}$ ). Line (a): single flash experiment, the dye laser $(650 \mathrm{~nm})$ illuminated the sample without a preceding flash, line (b): double flash experiment, the dye laser illuminated the sample after a delay of $40 \mathrm{~ms}$ following the first (photographic) flash. The recordings were triggered in both cases by the laser flash. Solution composition: $50 \mu \mathrm{M} \mathrm{CaCl}_{2}, \mathrm{pH} 7.5$, temperature $22^{\circ} \mathrm{C}$.

The delay time dependence of the time integral of the first electric signal is presented in Fig. 8 (solid squares). It begins at $3 \mathrm{~ms}$ with positive values and continues with negative values to about $500 \mathrm{~ms}$. Line

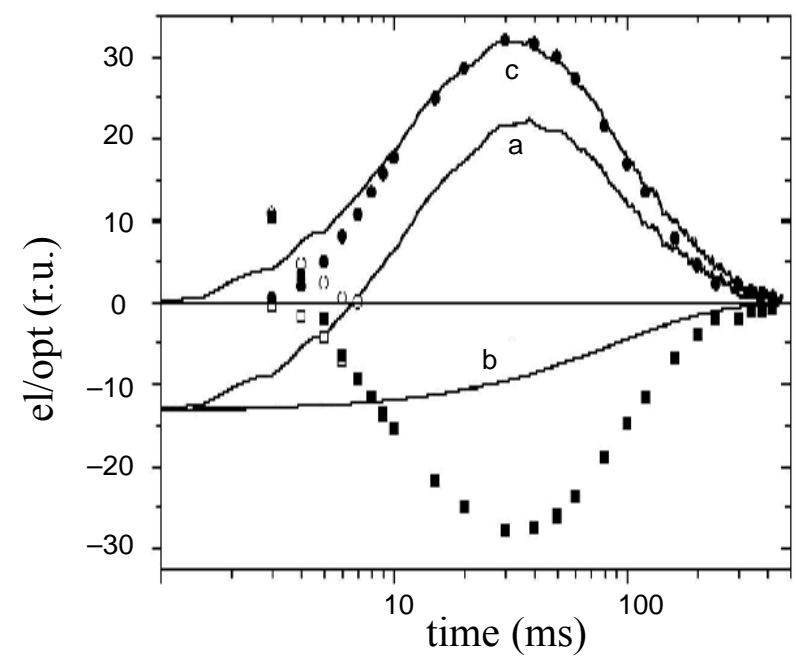

Figure 8. Processing of the electric and optical data for mutant E204Q. Line (a): absorption change at $632 \mathrm{~nm}$, line (b): calculated function for the bleaching of $\mathrm{bR},-13 \times \exp (-(t-$ $1) / 91$ ), with $t$ in $\mathrm{ms}$, line (c): difference of lines $\mathrm{a}$ and $\mathrm{b}$, representing the concentration of $O$. Solid squares: the integrated values of the first fast electric signals measured at different delay times after the first flash. Open circles: positive components subtracted as corrections to obtain the open squares. Combination of open and solid squares: the corrected data representing the $\mathrm{O}$ electric signal. Solid circles: the previous data scaled to line $c$. Solution composition as in Fig. 7. The first flash was the photographic flash lamp for the electric signals and Nd YAG laser for the absorption, the second flash was from the dye laser $(650 \mathrm{~nm})$. 
a is the absorption change at $632 \mathrm{~nm}$. It is corrected for bleaching of the bR-state using line $b$ to obtain line $\mathrm{c}$, the time course of the $\mathrm{O}$ concentration. Open circles accounting for positive signals are subtracted from the electric data (solid squares) yielding the open squares. The open squares (until $7 \mathrm{~ms}$ ) and the solid squares (after $7 \mathrm{~ms}$ ) are scaled to the time course of $\mathrm{O}$ (solid circles). The data differ somewhat from the time course of $\mathrm{O}$ at delays below $10 \mathrm{~ms}$ and above $100 \mathrm{~ms}$. We attribute the deviation below $10 \mathrm{~ms}$ to the uncertain correction for the positive contribution assigned to excitation of the $\mathrm{K}$ intermediate (the electric signal of $K$ is positive [16]) due to the flank in the light emitted by the photographic flash. Above $100 \mathrm{~ms}$ excitation of the recovering bR-state may cause uncertainties. Nevertheless, Fig. 8 is considered as evidence that the second flash excites mainly $\mathrm{O}$ in the time range from 10 to $100 \mathrm{~ms}$.

The electric and optical responses of $\mathrm{O}$ were studied in more detail at a delay time of $40 \mathrm{~ms}$. In addition to the components in Fig.7, negative and positive components with ms time constants were found (line a in Fig. 9). The final value of the time integral of the electric current, i.e. the transported charge is roughly zero (line b). The absorption change at $632 \mathrm{~nm}$ is given as line c. Lifetimes of the electric and optical signals are collected in Table 2. The lifetimes of the ms components agree adequately with each other.

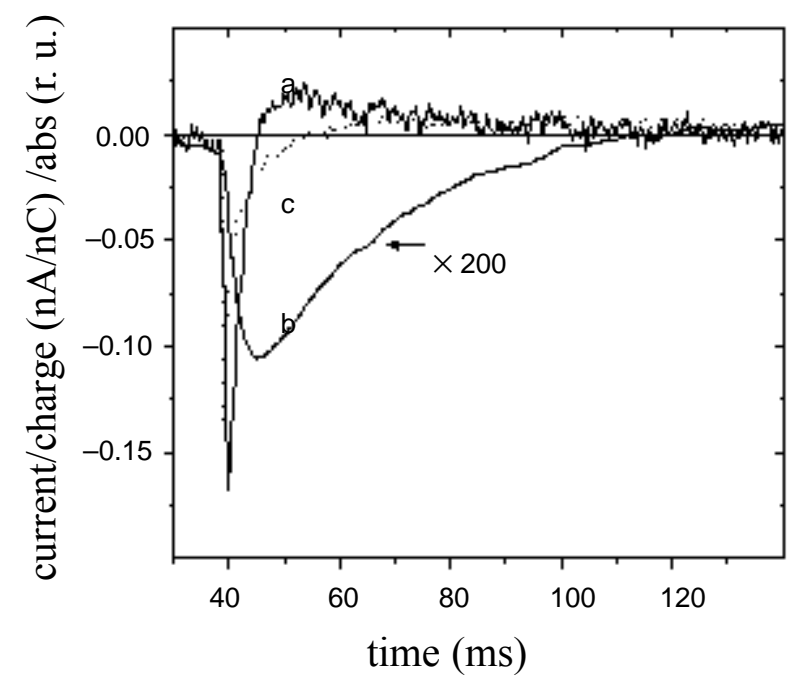

Figure 9. Electric and optical signals from excitation of $\mathrm{O}$ of mutant E204Q. The $650 \mathrm{~nm}$ laser flash illuminated the sample at a delay of $40 \mathrm{~ms}$ after the photographic flash. Line (a): current, line (b): time integral of the current, line (c): absorption change at $632 \mathrm{~nm}$. Solution composition as in Fig. 7.
Table 2.

\begin{tabular}{lllll}
\hline $\begin{array}{l}\text { Type of } \\
\text { signal }\end{array}$ & $\tau_{1}(\mu \mathrm{s})$ & $\tau_{2}(\mu \mathrm{s})$ & $\tau_{3}(\mathrm{~ms})$ & $\tau_{4}(\mathrm{~ms})$ \\
\hline Electric & $(+) 16.4 \pm 0.1$ & $81 \pm 4$ & $2.9 \pm 0.1$ & $22 \pm 2$ \\
Optical & n. d. & n. d. & $1.9 \pm 0.2$ & $15.6 \pm 0.4$ \\
\hline
\end{tabular}

Lifetimes of the components of the electric and optical signals from the $\mathrm{O}$ intermediate of the E204Q bacteriorhodopsin mutant.

( $\tau_{1}$ is the decay time of the first positive electric signal in Fig. 8, line $b) ; \tau_{2}, \tau_{3}$ characterize the decaying and rising part of the negative component, $\tau_{4}$ the decay of the positive component of the electric signal in Fig. 9 (line a). For the optical signal, $\tau_{3}$ and $\tau_{4}$ are the lifetimes of the decay.)

\section{DISCUSSION}

The electric response in the case of excitation of the bR-state of WTbR is a large, fast negative signal and adjoining positive components with $\mu$ s and $\mathrm{ms}$ time constants. The components have their counterparts in absorption [15]. These properties are used as references for discussing the electric responses of the excited $\mathrm{O}$ intermediates.

The electric signals for $\mathrm{O}$ are different in the $\mu \mathrm{s}$ time domain: the fast positive component is followed by a large negative one for WTbR but only a large negative component is found for E204Q (Figs 3 and 7). In the ms time domain, however, negative components followed by positive ones appear (Figs 4 and 9). Tables 1 and 2 demonstrate that the components of the electric and optical signals have similar time constants as those known for the photocycle of the bR-state. Naturally, at the present level of experimentation the photocycles of the $\mathrm{O}$ intermediates are not known, the data refer to absorption changes appearing only at $633 \mathrm{~nm}$. There is, however, an important difference between the $\mathrm{O}$ intermediates of WTbR and E204Q: the time integral of the electric signal is positive in the case of the WTbR indicating charge translocation and nearly zero in the case of mutant E204Q (Figs 4 and 9, lines b). The current measurements with quasi-continuous illumination showing positive current for red illumination of O (Figs 5 and 6) support the result in Fig. 4. Thus, our data demonstrate that the $\mathrm{O}$ intermediate of WTbR is a pump. Consequently, the $O$ intermediates of the two species deviate from each other: the $\mathrm{O}$ intermediate of WTbR translocates, whereas that of the mutant E204Q does not translocate charges, the electric signals indicate internal charge motions.

The retinal in O of WTbR was previously 
assigned as twisted all-trans [17], however, at that time the existence of the rapid $\mathrm{N} \leftrightarrow \mathrm{O}$ equilibrium was not taken into account. There are hints in the literature that the conformation of the retinal is probably 13-cis [18]. Our unpublished study of the mutant L93A with 13-cis O [18] strongly indicates that its $\mathrm{O}$ photocycle is a proton pump. The question arises whether the retinal configurations of $\mathrm{O}$ in WTbR and mutant L93A are similar.

\section{ACKNOWLEDGMENTS}

We are grateful to Prof. W. Stoeckenius for discussions and Prof. J. K. Lanyi for supplying the purple membrane containing mutant E204Q. This work was supported by the Hungarian National Science Fund (OTKA T025236).

\section{REFERENCES}

1. Lanyi, J. K. Mechanism of ion transport across membranes. Bacteriorhodopsin as a prototype for proton pump. J. Biol. Chem. 272 (1997) 3120931212.

2. Stoeckenius, W. Bacterial rhodopsins: evolution of a mechanistic model for the ion pump. Protein Sciences 8 (1999) 447-459.

3. Keszthelyi, L. Primary charge motion and lightenergy transduction in bacteriorhodopsin. Biophys. Chem. 29 (1988) 127-136.

4 Balashov, S. P. Photoreactions of the photointermediates of bacteriorhodopsin. Israel J. Chem. 35 (1995) 415-428.

5. Karvaly, B. \& Dancsházy, Zs. Bacteriorhodopsin: a molecular photoelectric regulator. Quenching of photovoltaic effect of bimolecular lipid membranes containing bacteriorhodopsin by blue light. FEBS Lett. 76 (1977) 36-40.

6. Hwang, S. B., Korenbrot, J. I. \& Stoeckenius, W. Transient photovoltages in purple membrane multilayers. Charge displacement in bacteriorhodopsin and its photointermediates. Biochim. Biophys. Acta 509 (1978) 300-317.

7. Ormos, P., Dancsházy, Zs. \& Keszthelyi, L. Electric response of a back photoreaction in the bacteriorhodopsin photocycle. Biophys. J. 31 (1980) 207-213.

8. Butt, H.-J., Fendler, K., Bamberg, E., Tittor, J. \& Oesterhelt, D. Inversion of proton translocation in bacteriorhodopsin mutants D85N, D85T, and D85/D95N. EMBO J. 8 (1989) 1657-1633.

9. Tóth-Boconádi, R., Szabó-Nagy, A., Taneva, S. G. \& Keszthelyi, L. Photoelectric response of the $\mathrm{N}$ intermediate of bacteriorhodopsin and its mutant T46V. FEBS Letters 459 (1999) 5-8.

10. Chizhov, I., Engelhard, M., Chernavskii, D. S., Zubov, B., \& Hess, B. Temperature and $\mathrm{pH}$ sensitivity of the $\mathrm{O}_{640}$ intermediate of the bacteriorhodopsin photocycle. Biophys. J. 61 (1992) 1001-1006.

11. Balashov, S. P., Lu, M., Imasheva, E. S., Govindjee, R., Ebrey, T. G., Othersen III, B., Chen, Y., Crouch, R. K. \& Menick, D. P. The proton release group of bacteriorhodopsin controls the rate of the final step of the photocycle at low pH. Biochemistry 38 (1999) 2026-2039.

12. Brown, S. L., Sasaki, J., Kandori, H., Maeda, A., Needleman, R. \& Lanyi, J. K. J. Glutamic acid 204 is the terminal proton release group at the external surface of bacteriorhodopsin. Biol. Chem. 27 (1995) 27122-27126.

13. Kandori, H., Yamazaki, Y., Hatanaka, M., Needleman, R., Brown, L. S., Richter, H-T., Lanyi, J. K. \& Maeda, A. Time resolved Fourier transform infrared spectroscopy of structural changes in the last steps of the photocycle of Glu204 and Leu93 mutants of bacteriorhodopsin. Biochemistry 36 (1997) 5134-5141.

14. Dér, A., Hargittai, P. \& Simon, J. Time resolved photoelectric and absorption signals from oriented purple membranes immobilized in gels. J. Biochem. Biophys. Methods 10 (1985) 295-300.

15. Keszthelyi, L. \& Ormos, P. Protein electric response signals from dielectrically polarized systems. J. Membr. Biol. 109 (1989) 193-200.

16. Ormos, P., L. Reinisch, \& L. Keszthelyi. Fast electric response signals in the bacteriorhodopsin photocycle. Biochim. Biophys. Acta 732 (1982) 471-479.

17. Smith, S. O., Pardoen, J. A., Mulder, P. P. J., Curry, B., Lugtenburg, J. \& Mathies, R. Chromophore structure in bacteriorhodopsin's $\mathrm{O}_{640}$ photointermediate. Biochemistry 22 (1983) 6141-6148.

18. Delaney, J. K., Schweiger, U. \& Subramaniam, S. Molecular mechanism of protein-retinal coupling in bacteriorhodopsin. Proc. Natl Acad. Sci. USA 92 (1995) 11120-11124. 